\title{
Application of a Detailed Emission Model for Heavy Duty Diesel Engine Simulations
}

\author{
I. Magnusson ${ }^{1}$ \\ 1 Volvo Technological Development Corp., dept 6110, PVO E21, S-40508 Gothenburg -Sweden \\ e-mail: ingemar@vtd.volvo.se
}

Résumé - Application d'un modèle détaillé d'émissions pour la simulation de gros moteurs Diesel Un modèle avec chimie détaillée décrivant la formation des suies et du NO est appliqué à la simulation de la formation des polluants dans un gros moteur Diesel. L'écoulement et le spray sont modélisés avec le code de calcul Speedstar. La combustion est représentée par le modèle « eddy break-up ». La modélisation de l'interaction entre l'écoulement turbulent et la chimie des polluants est basée sur une approche de type «flamelet». Cependant, à la différence d'autres travaux, des équations de transport pour les fractions massiques de suies et de NO sont résolues. Cela est justifié par la supposition que les temps caractéristiques de formation de ces composés sont longs comparés à ceux associés aux phénomènes de transport et aux réactions chimiques associées à la combustion. Cependant, les vitesses de réaction se rapportant aux suies et au NO sont supposées rapides. Cela permet d'évaluer les termes sources des suies et du NO à partir d'une bibliothèque de «flamelets » en utilisant une approche de type densité de probabilité présumée et en intégrant dans l'espace des fractions de mélange.

Les résultats de simulations sont comparés à des mesures à l'échappement d'un moteur ainsi qu'aux évolutions de la pression dans le cylindre.

Mots-clés : moteur, simulation, $\mathrm{NO}_{\mathrm{x}}$, suies.

\begin{abstract}
Application of a Detailed Emission Model for Heavy Duty Diesel Engine Simulations - A detailed chemical model describing the formation of soot and NO is applied to simulate emission formation in a heavy duty diesel engine. Cylinder flow and spray development is simulated using an engine CFD codeSpeedstar. Combustion is described using a simple eddy break-up model. Modeling of the emissionchemistry/turbulent-flow interaction is based on a flamelet approach. Contrary to a typical flamelet concept, transport equations are solved for mass fractions of soot and NO. The reason being that these major emission constituencies are assumed to change slowly in comparison to typical time scales for chemical processes or transport processes important for combustion. Chemical reactions leading to production and destruction of soot and NO are, however, assumed to be fast. Soot and NO source terms are therefore evaluated from a flamelet library using a presumed probability density function and integrating over mixture fraction space.
\end{abstract}

Results from simulations are compared to engine measurements in form of exhaust emission data and cylinder pressure.

Keywords: engine CFD, emission model, $\mathrm{NO}_{x}$, soot. 


\section{IN TRO DUCTIO N}

High fuel efficiency and low emission levels make today's diesel engine an attractive power source for automotive applications. However, since the engine operates with an overall lean fuel/air mixture, no general after-treatment system is yet available. Further decrease of emission levels must therefore originate from improvements of the basic combustion system. To facilitate future engine development improved knowledge of basic combustion processes is needed, including a detailed understanding of the complex kinetic processes involved in emission formation and a description of the interaction between chemical processes and the turbulent flow field within the engine. Numerical tools with predictive capabilities for emission formation should be developed.

In the present work an emission model with a potential to become predictive is briefly described and some preliminary results are reported. Two engine operating conditions are simulated and a comparison is made to measured engine data.

\section{METHOD}

\subsection{CFD Calculation}

Engine flow, spray development and combustion was calculated with the Speedstar CFD code [1] using: a standard $k$ - $\varepsilon$ model for turbulence, the Huh-Gosman model [2] for spray atomisation and the Magnussen model [3] for combustion. The calculation was performed for closed valve conditions and simple initial conditions were given to the flow field corresponding to zero swirl. Only a sector of the engine cylinder was meshed as displayed in Figure 1 assuming equal conditions for the eight sprays. Maximum size of the mesh was 24000 cells.

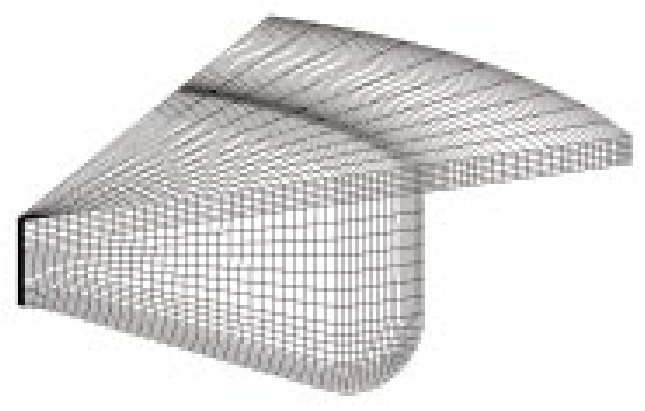

Figure 1

Numerical mesh

\subsection{Soot Model}

The soot model has been described elsewhere $[4,5]$ and only a few details are given here. A detailed chemical soot model is stored in a flamelet library with temperature of fuel, $T_{f}$, temperature of air, $T_{a}$, scalar dissipation rate, $X$, pressure, $P$, and mixture fraction, $Z$, as parameters. These parameters are all calculated by the CFD code at each grid point. In addition an equation for the mixture fraction variance is solved. The variance and the mean value of the mixture fraction define a presumed $\beta$-function PDF of mixture fraction which is subsequently used to perform weighted averages taking turbulent fluctuations into account. Contrary to other types of flamelet concepts $[6,7]$ a transport equation is solved for the soot mass fraction. The underlying assumption being that the growth of soot particles is slow in comparison to other chemical reactions or transport processes in the flame. The chemical reactions leading to formation and destruction of soot are, however, assumed to be fast and flamelet-like. The flamelet soot model gives as an output 4 types of soot sources corresponding to particle inception, fragmentation, surface growth and oxidation respectively. The interaction between the CFD code and the soot model is illustrated in Figure 2.

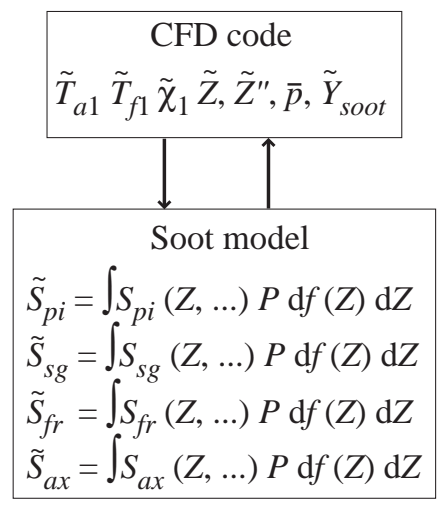

Figure 2

Interaction between CFD code and the soot model.

\section{$1.3 \mathrm{NO}_{\mathrm{x}}$ Model}

The formation of $\mathrm{NO}_{\mathrm{x}}$ is modelled similarly to the formation of soot. A transport equation is solved for the mass fraction of the major species NO whereas source terms are stored in a flamelet library. The implementation of the $\mathrm{NO}_{\mathrm{x}}$ model is still at an immature stage in the sense that only the simple Zeldovich mechanism is used and only the forward reaction of that mechanism. The results from the model should therefore be considered only as rough indications. 


\subsection{Engine Specification}

Characteristic engine data is given in the Table 1.

TABLE 1

Engine data

\begin{tabular}{l|l}
\hline Type & Volvo D12a \\
\hline Compression ratio & 17.5 \\
\hline Bore & $131 \mathrm{~mm}$ \\
\hline Stroke & $150 \mathrm{~mm}$ \\
\hline Fuel injection & unit injector \\
\hline Nozzle hole & $0.20 \mathrm{~mm}(\times 8)$ \\
\hline Fuel & Diesel \\
\hline Injection timings & $357 \mathrm{c.a}$. and $360 \mathrm{CA}$ \\
\hline Speed & $1500 \mathrm{rpm}$ \\
\hline Closed valves period & $220 \mathrm{CA}-478 \mathrm{CA}$ \\
\hline
\end{tabular}

\section{RESULTS}

The capability of the Speedstar code to describe spray and combustion is indicated by the calculated cylinder pressure. The agreement between calculated and the measured curves is satisfactory as illustrated in Figure 3 for both engine operating conditions.

The calculated cylinder mass of soot is shown in Figure 4. Only a few percent of the soot originally formed is left at the end of the expansion stroke which is in agreement with similar calculations [6]. The level of soot at the time for exhaust valve opening is in encouragingly close agreement with measured values in the exhaust gas.

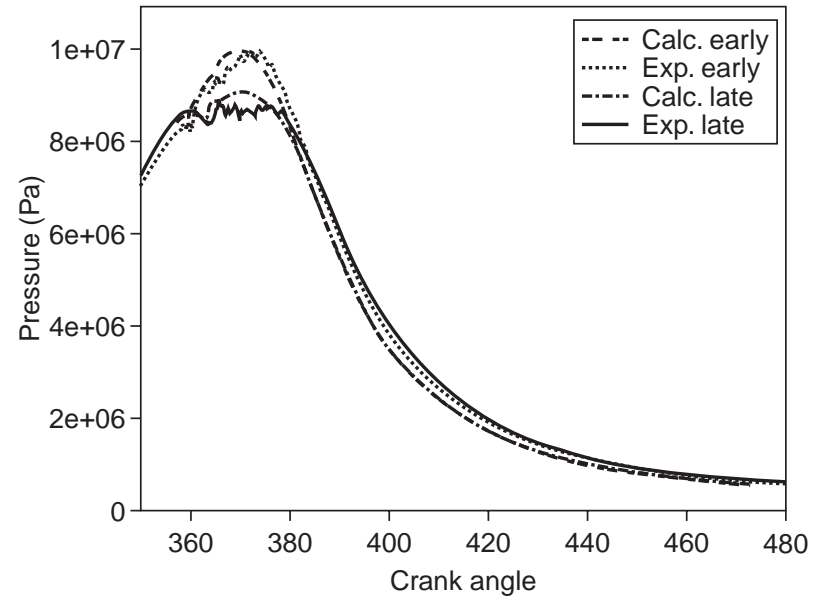

Figure 3

Calculated and measured cylinder pressure for engine operating conditions corresponding to early and late injection timing.
Results from $\mathrm{NO}_{x}$ modelling is given in Figure 5. The calculated levels of NO are clearly higher than those measured in the exhaust. One obvious explanation for the over-prediction is the lack of backward reaction in the preliminary model implementation. However, the trend in NO level when going from early to late injection seems to be well reproduced also with the present model.

The calculated local distribution of NO is shown in Figure 6 at a crank angle of 367 corresponding to $10 \mathrm{CA}$ after start of injection for the early injection case. At this crank angle the fuel has already reached the wall of the piston bowl as seen illustrated in the same figure. High NO concentrations

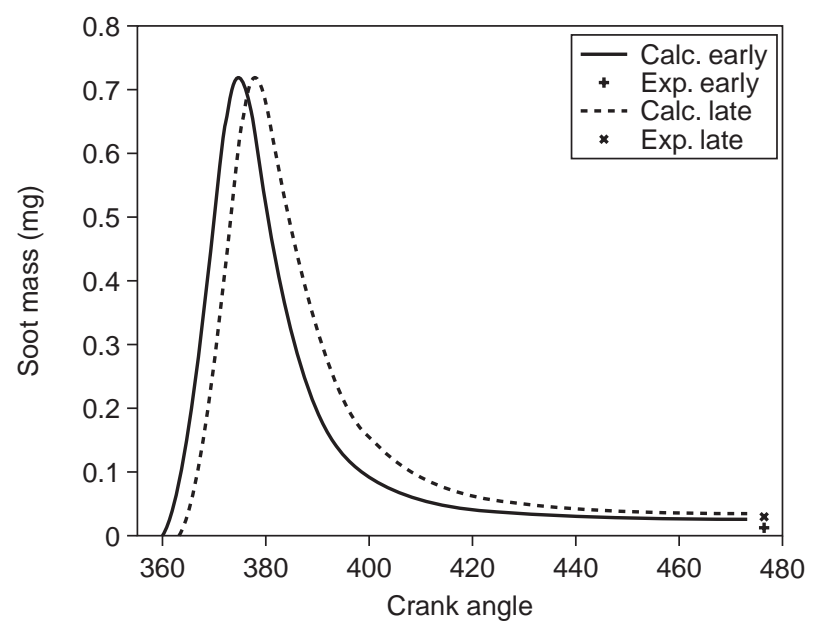

Figure 4

Total calculated mass of soot in the cylinder and experimental data in exhaust gas.

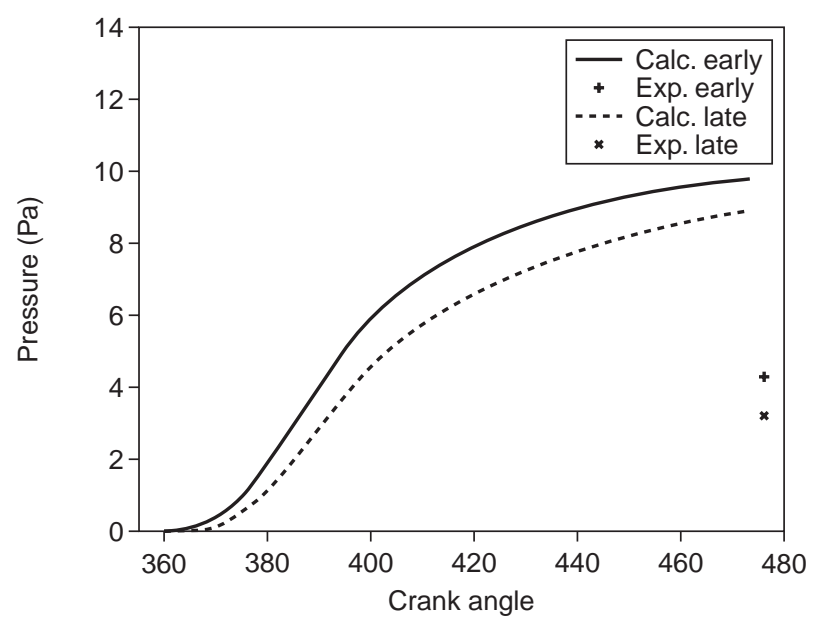

Figure 5

Total calculated mass of $\mathrm{NO}$ in the cylinder and experimental $\mathrm{NO}_{\mathrm{x}}$ data in exhaust gas. 

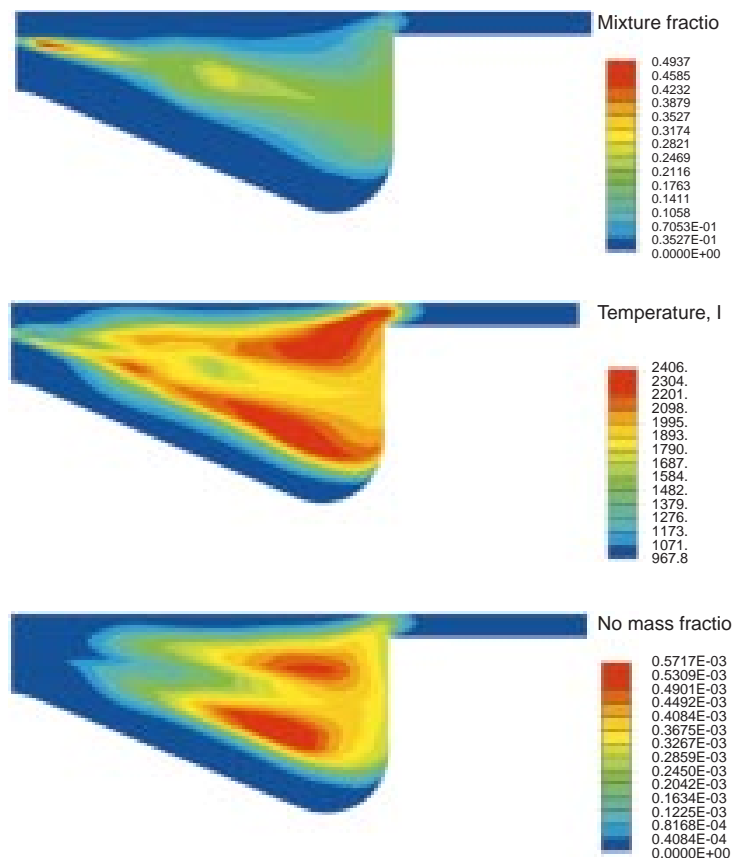

Figure 6

Calculated results for the early injection case in form of mixture fraction, temperature and $\mathrm{NO}$ at $367 \mathrm{CA}$. in a vertical section aligned with the spray axis.
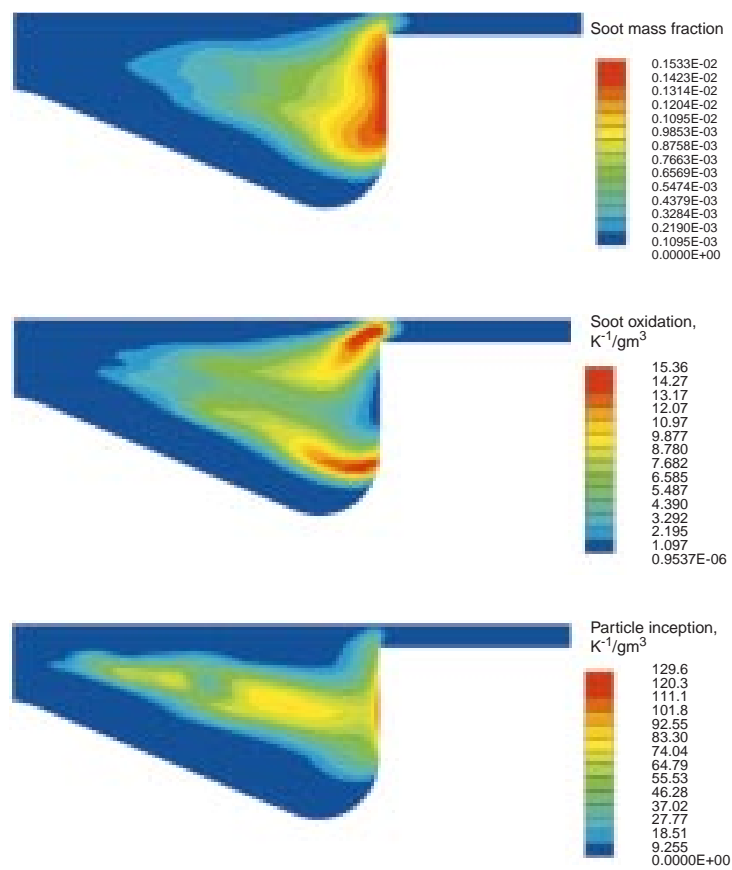

Figure 7

Calculate results for the early injection case in form of soot mass fraction, soot oxidation rate and particle inception rate at $367 \mathrm{CA}$ in a vertical section aligned with the spray axis. are found in regions with close to stoichiometric mixture fraction, regions in which also the temperature is high.

The highest soot concentrations are found in regions with high mixture fraction at the tip of the spray as displayed in Figure 7. In the latter figure also the distribution of two soot formation processes are presented. It is interesting to note that soot oxidation predominately takes place in the high temperature regions in which NO production is high. The fact that local conditions that favour soot oxidation also favour NO formation is a probable major reason for the well known soot- $\mathrm{NO}_{\mathrm{x}}$ trade off typically encountered when optimising diesel engines. Soot production as given by the particle inception rate has a spatial distribution with strong correlation to the mixture fraction field. The absence of soot formation close to the injector, to the left in the figure, is due to the very high scalar dissipate rate in that region.

\section{CONCLUSION}

Calculations using a flamelet type of emission model have given encouraging results in good agreement with measured engine data. The results obtained at this stage are, however, preliminary and thorough testing and optimisation of the model remain.

\section{ACKN OW LEDG MENTS}

The Lund team: Michael Balthasar, Anne Dederichs and Fabian Mauss are thanked for a good collaboration. The assistance in numerical implementation by Thomas Hellström at Volvo is greatly acknowledged.

\section{REFEREN CES}

1 Gosman, A.D., Krajl, C., Marooney, C. and Theodossopoulos, P. (1992) Development Strategies for Diesel Combustion Simulation Using the Speed Code. I. Mech., C448/035.

2 Huh, K.Y. and Gosman, A.D. (1991) International Conference on Mutliphase Flows, Tsukuba.

3 Magnussen, B.F. and Hjertager, B.H. (1976) Proc. 16th Int. Symposium on Combustion, Combustion Institute.

4 Karlsson, A., Magnusson, I., Balthasar, M. and Mauss, F. (1995) Simulation of Soot Formation under Diesel Engine Conditions Using a Detailed Kinetic Soot Model, SAE Paper No. 981022.

5 Balthasar, M., Heyl, A., Mauss, F., Schmitt, F., Bockhorn, H. (1996) Flamelet Modeling of Soot Formation in Laminar Ethyne/Air Diffusion Flames. 26th Symposium (International) on Combustion, Naples, 2369.

6 Pitsch, H., Wan, Y.P. and Peters, N. (1995) Numerical Investigation of Soot Formation and Oxidation under Diesel Engine Conditions, SAE Paper No. 952357.

7 Peters, N. (1984) Laminar Diffusion Flamelet Models in Non-Premixed Turbulent Combustion. Prog. Energ. Combust. Sci., 10, 319-339.

Final manuscript received in March 1999 